\title{
Why Changes in Price Matter When Thinking About Marijuana Policy: A Review of the Literature on the Elasticity of Demand
}

\author{
Rosalie Liccardo Pacula, $\mathrm{PhD},{ }^{1,2}$ \\ Russell Lundberg, $\mathrm{PhD}^{1}$
}

\begin{abstract}
Recent debates regarding liberalization of marijuana policies often rest on assumptions regarding the extent to which such policy changes would lead to a change in marijuana consumption and by whom. This paper reviews the economics literature assessing the responsiveness of consumption to changes in price and enforcement risk and explicitly considers how this responsiveness varies by different user groups. In doing so, it demonstrates how most of the research has examined responsiveness to prevalence of use, which is a composite of different user groups, rather than level of consumption among regular or heavy users, which represent the largest share of total quantities consumed. Thus, it is not possible to generate reliable estimates of the impact of liberalizing policies on either tax revenues or harms, as these outcomes are most directly influenced by the amounts consumed by regular or heavy users, not prevalence rates.
\end{abstract}

Key Words: Marijuana, price, price elasticity of demand

Recommended Citation: Pacula RL, Lundberg R. Why changes in price matter when thinking about marijuana policy: a review of the literature on the elasticity of demand. Public Health Reviews. 2014;35: epub ahead of print.

\section{INTRODUCTION}

A vast literature has developed over the past 20 years examining the etiology of and factors influencing marijuana consumption. Economists have contributed to this literature by demonstrating the relative importance of changes in the full price of marijuana on marijuana use and drug use careers. The typical approach used by economists to describe how sensitive

\footnotetext{
${ }^{1}$ RAND Corporation, Santa Monica, CA, USA.

${ }^{2}$ National Bureau of Economic Research, Cambridge, MA, USA.
}

Corresponding Author Contact Information: Rosalie Liccardo Pacula at pacula@ rand.org; RAND Corporation, Santa Monica, CA, USA. 
a user is to changes in the price of a good is the "price elasticity of demand." The price elasticity of demand measures how much consumption of a good changes (in percentage terms) in response to a one percent change in the price of that good holding all other factors constant. As demand for most goods is downward sloping, the price elasticity of demand is generally negative indicating that when price goes up consumption goes down. A value less than one in absolute value (that is, between 0 and 0.99 ) is generally considered to be "inelastic" or less responsive to price changes because consumption changes (in percentage terms) less than price changes (in percentage terms). A value greater than one in absolute value is generally considered to be "elastic", because the percentage change in consumption observed with a one percent change in price is greater than that for price.

Discussion of the price elasticity of demand for marijuana has grown recently in light of debates about marijuana legalization in the United States and abroad. However, many who draw on this literature to substantiate a particular position regarding legalization do so naively, unaware that the responsiveness of consumption to price can depend on where in the distribution of marijuana users the sample is drawn. Marijuana markets, like markets for other goods, are characterized by a number of different types of consumers, all of whom contribute in varying amounts to the total amount consumed in the market ${ }^{1-3}$ and researchers have been careful to consider the type of user in constructing estimates of use. ${ }^{4,5}$ Yet, reviews of the literature on the price sensitivity of demand often ignore these important differences.

This paper contributes to the existing economic and policy literatures on the demand for marijuana and the probable impact of policy on consumption by clearly differentiating the findings from the literature regarding the price elasticity of demand by different types of user groups. In doing so, it becomes readily apparent that various groups might respond differentially to a policy change. In particular, this paper considers how responsive consumption has been to various components of the full price of marijuana, which captures both the monetary aspect of price as well as the non-pecuniary aspects of price, such as the legal risk of using it and/or the perceived health risks. The four user groups considered are 1) initiators and light users - new users who are experimenting with marijuana or consuming small doses on a very infrequent basis; 2) regular users - individuals who consume in relatively small or moderate doses on a more frequent basis; 3 ) heavy users - individuals who consume on a near daily basis or who meet Diagnostic and Statistical Manual of Mental Disorders (DSM-IV) criteria for dependence or abuse; and 4) quitters - individuals who are deciding to no longer use marijuana. 
Our thesis is that consumption by each of these groups will be differentially impacted by price changes and thus prevalence rates by themselves are imperfect indicators of real consumption changes caused by price changes. Prevalence rates conflate changes in the behaviors of new initiates and casual users with the behaviors of regular or heavy users. Although new initiates and casual users represent a large proportion of the total number of users, they represent a very small amount of the total quantity of the drug consumed. ${ }^{1,3,5}$ Estimates of a price decrease of more than 80 percent ${ }^{6,7}$ would have very different implications for light users, who spend a very small share of their income on marijuana, than on more regular or heavy users, who spend more of their disposable income on the good.

\section{DISCUSSION}

\section{The Responsiveness of Initiation}

If the goal is to understand factors influencing marijuana initiation, then one must start by looking at use among adolescents. While not all individuals who initiate marijuana are adolescents, the average age of initiation of marijuana among those reporting in the household population is just under the age of $18 .^{8}$ Thus data on adolescent marijuana initiation can contribute insights into initiation generally.

Research into factors associated with marijuana initiation and use by adolescents has generally focused on non-monetary aspects of price, including perceived harm and disapproval. ${ }^{9,10}$ However, monetary price is also important. Pacula et al. examined the relative importance of price and non-monetary harms in predicting trends in use over time. ${ }^{11}$ While perceived harm and disapproval were important, and played a larger role in the period of expanded use, changes in purity-adjusted price contributed significantly to the trends in youth annual and 30-day use rates from 1982 to 1998, and particularly in the contraction of use from 1982 to 1992. Annual participation elasticities from this study fell in the range of -0.06 to -0.47 , while 30 -day participation elasticities generated a wider range of -0.002 to -0.69 . Their preferred specification identified a price elasticity for both annual and 30 -day prevalence of -0.30 , implying that a ten percent reduction in the price of marijuana would lead to a three percent increase in the number of high school seniors reporting past year and past month use.

Other studies have looked at the impact of price on annual and 30-day prevalence of use among high school or elementary students and found negative and statistically significant relationships, but the effect sizes have 
been small and participation elasticities are not reported. ${ }^{11-13}$ Two Australian studies look more directly at the impact of price on initiation using duration models. van Ours \& Williams and Bretteville-Jensen \& Williams both examined initiation among youth and young adults in Australia and found marijuana price to be negatively associated with initiation. ${ }^{14,15}$ In Van Ours \& Williams, the initiation elasticity ranged from -0.31 to -0.70 , with their preferred specification generating a past year initiation elasticity of -0.50 . Bretteville-Jensen \& Williams built on this work and found that initiation was driven by the sample of youth under the age of 18 and the monetary price of marijuana was not statistically significant for predicting initiation of marijuana for individuals after age 18 .

As economists interpret price more broadly to also include the nonpecuniary aspects of using a good (e.g., the legal risks, the health risks, the search costs), many studies have considered the responsiveness of consumption to decriminalization status and legal risks of using marijuana. In one of the earliest studies of the effects of state decriminalization policies, Johnston et al. compared marijuana use in the 1970s across states and found no evidence that the decriminalization of small amounts of marijuana in California in 1976 increased use. ${ }^{16}$ DiNardo \& Lemieux found a similar null effect of decriminalization in 30-day prevalence rates for high school seniors in the 1980s. ${ }^{17}$ However, these two studies did not include any additional measures of legal risk in their models, which is problematic as subsequent papers found that the effects of decriminalization are only apparent when additional measures of legal risk or monetary price of marijuana are included. ${ }^{18,19}$

Studies that included additional measures of the legal risk of consuming marijuana or the monetary price of marijuana have generally found that marijuana decriminalization has a positive and statistically significant effect. ${ }^{20-22}$ Using data from the Monitoring the Future Survey, Chaloupka, Grossman \& Tauras found that decriminalization was associated with higher prevalence of marijuana use in the past year but not in the past month when state-level fines were also included..$^{20}$ Additionally, they found that among those who report some use, decriminalization was not associated with frequency of use, suggesting that the legal risk deters initiation but does not deter consumption once someone starts to use. Chaloupka et al. found broader effects when including an additional measure of median jail time served," with decriminalization status coming in positive and statistically significant

\footnotetext{
* As eighth and tenth graders were included in this sample, 30-day use will largely reflect new initiation or casual experimentation with marijuana.
} 
in both the 30-day prevalence and conditional frequency equations. ${ }^{21}$ Finally, Pacula, Chriqui \& King, in an examination of tenth grade students, found decriminalization to be statistically significant above and beyond actual penalties (such as changes in criminal status, reduced time in jail, lower fines, and relative enforcement). ${ }^{12}$

In addition to the effects of general decriminalization are the costs of the expected punishment. The expected punishment depends on both the severity of a punishment and the likelihood that the punishment will be carried out. In marijuana policy research, severity is often measured using fines or time in jail while the likelihood of punishment is often associated with the intensity of police enforcement. Chaloupka, Grossman \& Tauras found fines to be associated with lower annual and 30-day prevalence of marijuana and lower frequency of use among users, ${ }^{20}$ while Chaloupka et al found statistically significant effects only with regards to fines ${ }^{21}$ and Pacula, Chriqui \& King found them only with regards to jail time. ${ }^{12}$ Farrelly et al. (2001) examined the effect of average fines and without consideration of decriminalization in a US nationally representative sample of youth between the ages of 12 to $20 .{ }^{22}$ They found that youth living in states with higher average fines had lower rates of use, but not lower levels of use among those who used marijuana already, suggesting the deterrent effect was on the decision to use not the quantity consumed.

Table 1 summarizes the findings with respect to the effects of the monetary price, decriminalization, and the legal risk (penalties and police enforcement) of marijuana on the decision to use marijuana among youth. Marijuana initiation among youth is very sensitive to changes in the price of marijuana with plausible initiation elasticities from -0.3 (in Pacula et al. ${ }^{11}$ ) to -0.5 (in van Ours $\left.\& W i l l i a m s^{14}\right)$. The literature suggests that policies that reduce the price of marijuana by ten percent therefore, will lead to a three to five percent increase in the number of new marijuana users among youth, all else equal. The findings with respect to legal risks also suggest that youth are sensitive to changes in statutory penalties, although there is some inconsistency from study to study as to whether youth prevalence rates are more sensitive to jail sentences or fines. In most cases, the impact of the legal risk on prevalence is generally small, and when frequency of marijuana use is examined, legal risks are generally insignificant. The effects of decriminalization are less clear from the literature, which may be due to a combination of weak analytic approaches, the non-uniqueness of this policy in terms of actual penalties faced by users, and the apparent lack of knowledge about these policies. ${ }^{12,23,24}$ As there has been very little variation in decriminalization policies in the US between the early 1980s and mid-2000s, it is difficult to infer anything from studies relying on variation in state policies. ${ }^{12}$ 
Table 1

Findings Related to Impact of Price on Initiation of Marijuana

\begin{tabular}{l|l|l}
\hline $\begin{array}{c}\text { Economic Variable } \\
\text { of Interest }\end{array}$ & Summary Estimates & \multicolumn{1}{c}{ Studies } \\
\hline Monetary price & $\begin{array}{l}\text { Participation } \\
\text { elasticities range } \\
\text { from -0.002 to -0.69 }\end{array}$ & $\begin{array}{l}\text { Pacula et al. }(2001)^{11} \\
\text { Pacula, Chriqui \& King }(2003)^{12} \\
\text { DeSimone \& Farrelly }(2003)^{32} \\
\text { Jacobson }(2005)^{13} \\
\text { van Ours \& Williams }(2007)^{14} \\
\text { Bretteville-Jensen \& Williams }(2010)^{15}\end{array}$ \\
\hline Decriminalization & $\begin{array}{l}\text { Mixed results } \\
\text { inconclusive }\end{array}$ & $\begin{array}{l}\text { Johnston, O'Malley \& Bachman }(1981)^{16} \\
\text { Chaloupka, Grossman \& Tauras }(1999)^{20} \\
\text { Chaloupka et al. }(1999)^{21} \\
\text { DiNardo \& Lemieux (2001) } \\
\text { Pacula, Chriqui \& King }(2003)^{12}\end{array}$ \\
\hline Penalties (fine, jail) & $\begin{array}{l}\text { Mixed results; even } \\
\text { significant effects are } \\
\text { small }\end{array}$ & $\begin{array}{l}\text { Chaloupka, Grossman \& Tauras }(1999)^{20} \\
\text { Farrelly et al. }(2001)^{22} \\
\text { Pacula, Chriqui \& King }(2003)^{12} \\
\text { Markowitz \& Tauras }(2009)^{18}\end{array}$ \\
\hline Police enforcement & $\begin{array}{l}\text { Participation } \\
\text { elasticities range } \\
\text { from 0 to -0.287 }\end{array}$ & $\begin{array}{l}\text { Farrelly et al. (2001) })^{22} \\
\text { DeSimone \& Farrelly }(2003)^{32} \\
\text { Pacula, Chriqui \& King }(2003)^{12}\end{array}$ \\
\hline
\end{tabular}

\section{The Responsiveness of Regular Use}

The economics literature typically defines "regular users" as individuals who report use on a monthly basis (reporting that they used in the past 30 days or at least 12 times in the past year). Clearly, this is a very imprecise measure of regular marijuana users and could easily capture new initiates as well. However, nationally representative data provide no other, more reliable measure. As with initiation, regular use is also associated with a specific age group, as epidemiological data consistently demonstrate that regular use of marijuana peaks during young adulthood. According to the US 2008 National Survey on Drug Use and Health (NSDUH), the rate at which people report using marijuana in the past month more than doubles from teens under 18 to adults ages 18-25, and then declines with age after 30. Therefore, we focus on studies of young adults in particular when trying to understand the responsiveness of behavior among "regular users."

The literature examining the consumption behavior of regular users is larger than that for any other user group, however the vast majority of the work focuses on prevalence, not frequency of use. Table 2 provides a summary of some key studies that have considered various components of 


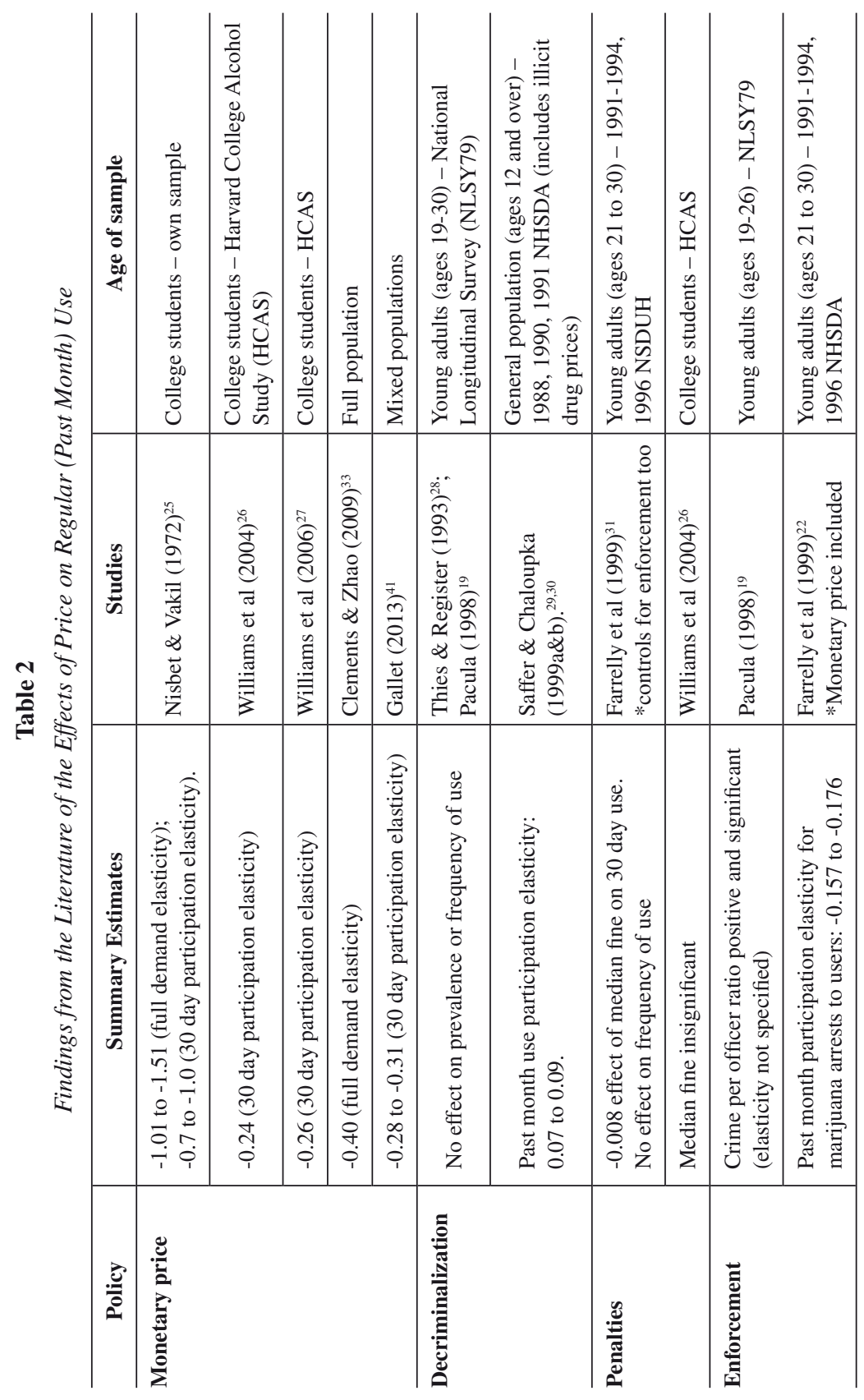


the full price on consumption among young adults. Several more studies reviewed herein consider changes in annual prevalence rates or apply to the general adult population, but these studies are excluded from the summary table so as to focus attention on studies targeting regular users, as defined above. As age still varies considerably even among the regular user population, we indicate in an extra column of Table 2 the age of the sample considered.

The first study to examine the price elasticity of demand for marijuana examined a population of American undergraduate students. Nisbet \&Vakil inquired about students' marijuana use in the past 30 days to estimate the effect of price both on the decision to use and the amount consumed. ${ }^{25}$ Their estimates of the price elasticity of marijuana participation for this group ranged from -0.7 to -1.0 , while the total elasticity of demand, which captures changes in average consumption among those already using as well as the decision to use, ranged from -1.01 to -1.51 . The elasticities derived from this study suggest that the total demand for marijuana is actually quite sensitive to changes in price." Two other papers focused on the behavior of college students and found statistically significant price elasticities. Williams et al. (2004) estimated a past month marijuana participation elasticity for a nationally representative sample of American college students age 18-24 of -0.24, controlling for alcohol use as well as unobserved heterogeneity ${ }^{26}$ They also included a measures of the maximum fine for possession of small amounts of marijuana and found when state fixed effects were included the legal penalty had no effect on consumption for this group. In a follow-on study in which younger students were differentiated from older students and cocaine use was also accounted for, Williams et al. (2006) found a lower annual participation elasticity for young college students less than 21 of -0.16 and a higher participation elasticity for older students of $-0.26 .^{27}$

Other studies examining demand responsiveness using US populations of regular users have examined non-monetary aspects of price. Studies that only include a measure of decriminalization status generated mixed conclusions. For example Thies and Register found decriminalization to have no effect on the annual or 30-day prevalence of marijuana or the frequency of use among young adults, ${ }^{28}$ while a series of papers by Saffer \& Chaloupka found positive and statistically significant effects of marijuana decriminalization on both

* We focus on findings from this study reported for an actual price change rather than responses to a hypothetical price change, as these data are deemed more reliable. 
past year and past month use. ${ }^{* 29,30}$ However, studies that included actual penalties and/or enforcement risk instead of decriminalization status found that consumption is sensitive to small differences in legal risks. ${ }^{20,31}$ Farrelly et al. (1999) suggested that a ten percent increase in the proportion of marijuana users arrested for possession would be associated with a 1.6 percent to 2.0 percent reduction in the prevalence of marijuana use among young adults. ${ }^{* *}, 31$ Higher median fines were also associated with reduced monthly prevalence, although the effect size is small-a ten percent increase in the median fine is only associated with a 0.08 percent reduction in prevalence. Conditional quantities consumed were not considered in this analysis.

Several studies have examined the responsiveness of annual prevalence rates and frequency of use (i.e., "conditional demand") to changes in the full price of marijuana. The problem with using annual prevalence rates rather than past month prevalence rates to consider the responsiveness of regular users is that annual prevalence rates combine the behavior of new initiates and more persistent users, particularly for individuals past the age of initiation. Nonetheless, the general findings even for these models are supportive that consumption is sensitive to changes in the full price of marijuana. DeSimone \& Farrelly, for example, estimated models of annual prevalence and frequency of marijuana use among 18-39 year olds. ${ }^{32}$ They found very clear negative effects of marijuana enforcement on both prevalence and frequency of marijuana use, suggesting that greater enforcement reduces marijuana use above and beyond any effect this might have on marijuana prices. They also find a negative relationship between marijuana prices and marijuana use, although the results are sensitive to the inclusion of state geographic fixed effects which is not surprising given the limited variability they have in price over the short period of time examined. Rhodes et al. (2001) also estimated a negative price elasticity in their models employing the entire household population (ages 12 years and older) using the US National Household Survey on Drug Abuse (NHSDA). Their estimate of the annual price elasticity of demand was $-0.33 .^{33}$

\footnotetext{
* In their second paper (Saffer \& Chaloupka, $1999 \mathrm{~b}^{30}$ ) that examines differences across gender and ethnicity in past year participation, they find that the positive effect of decriminalization holds for all subgroups except Native Americans. Living in a decriminalized state increases the probability of reporting use in the past year from 2\% (for Asians and African Americans) to $4 \%$ for Hispanics and individuals under the age of 21.

** It is interesting to note that the results for youth ( $<18$ years) in this analysis are different from those published by a subset of the group in 2001. The differences are likely due to changes in the exact specification of the model, but again raise the sensitivity of drawing firm conclusions from any one particular study.
} 
There is also evidence from international work demonstrating the sensitivity of consumption to changes in the price of marijuana when annual measures of use are utilized. ${ }^{34-39}$ For example, Ramful $\&$ Zhao found that marijuana prices were significantly associated with the probability of using marijuana for individuals who also use cocaine and heroin, but not for the unconditional sample of marijuana users. ${ }^{35}$ Similarly Williams \& Mahmoudi, using earlier waves of the Australian National Drug Strategy Household Survey, found that while annual prevalence rates were negatively associated with price, it was the group of individuals who report using both marijuana and alcohol (polydrug users) that drove that result. Studies examining the level or frequency of marijuana use among past year users generally found that these measures were unaffected by changes in price..$^{39,40}$ The lack of a significant effect of price on the frequency of consumption in these Australian samples differs from findings using US data.

In an effort to understand the extent to which population differences drove differences in findings regarding price elasticities, Gallet conducted a meta-analysis, building a model based on findings from 82 estimates from 13 studies of Australia and India as well as the US. ${ }^{41}$ Gallet did not attempt to distinguish between different types of users, as we do here, but he still generates non-zero estimates of participation elasticities based on his metaanalysis in the range of -0.28 to -0.31 . Follow up discussions with the author revealed that the conditional demand elasticity generated from the model for marijuana was estimated to be -0.15 . Thus the findings from the meta-analysis reinforce the conclusion that in the US changes in the monetary price of marijuana do influence both the prevalence of marijuana use and conditional quantity consumed.

\section{Responsiveness of Heavy Use}

Little work has been done explicitly examining the sensitivity of heavy or dependent use to changes in the full price of marijuana. In an early study of the impact of marijuana decriminalization on marijuana use, Model identified that states that adopted decriminalization policies experienced a 56 to 64 percent increase in marijuana-involved emergency department episodes compared to states who did not adopt these policies. ${ }^{42}$ However, she also found a significant decline in the number of episodes involving other illicit drugs in states that adopted these policies, suggesting a possible substitution of marijuana for these harder substances. Measures of marijuana prices and enforcement risk were not included in her model, however.

Other studies have examined marijuana use among arrestees. Arrestees are a population that is heavily engaged in drug use, with over 60 percent of arrestees testing positive for marijuana use via urine samples in the US, 
the United Kingdom and Australia. ${ }^{43}$ Pacula and Kilmer found that use both in the past 30 days and in the 72 hours before the crime was committed were negatively associated with self-reported price. ${ }^{44}$ The lack of a potencyadjusted price limited the ability to create a specific price elasticity of demand, but the strong association did suggest that consumption is sensitive to changes in price even in a group of heavy users. Grossman linked external price data that adjusted for average potency to arrestee selfreported use data and found statistically significant price effects. His estimates of the price elasticity depended on the specification of the model, but fell in the range of -0.26 to $-1.18 .{ }^{45}$ Finally, Rhodes et al. found a very high elasticity of marijuana demand among arrestees, from -2.65 to $-2.79 .{ }^{33}$

\section{Responsiveness of Quit Behavior}

Economists have only recently begun to model the decision to quit using. The only published work including measures of the monetary price on the decision to quit is the work by van Ours \& Williams. ${ }^{14}$ In their analysis of young users (under the age of 23) in Australia, they found that the monetary price of marijuana generally had a positive, although statistically insignificant, effect on the likelihood of quitting marijuana in the past year. Considered along with other studies that found that marijuana prices were correlated with the decision to initiate drug use early ${ }^{46,47}$ they suggest their findings show that higher marijuana prices still reduce the duration of the typical use career, but they do so by delaying initiation rather than enticing the user to quit.

\section{RECOMMENDATIONS}

It is now better understood that marijuana markets share some common characteristics with markets of other intoxicating goods. In particular, like alcohol, the casual user of marijuana represents a relatively large share of the proportion of people who report using any marijuana in the past year, but they represent a very small proportion of the total amount consumed. ${ }^{1-5}$ This realization implies that knowledge of how prevalence rates change in response to a change in price may not be that useful for understanding how total consumption would change with a change in price because of the heterogeneity in users represented by any particular prevalence rate. To understand how total consumption (in terms of volume of the good consumed) changes, one needs to understand how behavior among regular users and heavy users changes. Participation elasticities, generated from studies examining how annual or 30-day prevalence rates change as the price of marijuana changes, represent the bulk of the estimates from the literature on 
elasticities so far. Far less time and attention has been given in the literature to precisely estimating the sensitivity of amount consumed or heavy use.

Manning, Blumberg \& Moulton were the first to carefully document the fact that the price elasticity of demand changes over the distribution of users. ${ }^{48}$ Their analysis focused on drinkers and they found that the price elasticity of demand followed more of a U-shaped pattern. While, drinkers in the far tail of the distribution $\left(90^{\text {th }}\right.$ percentile) were not responsive to higher prices and behaved more like abstainers and light drinkers, drinkers consuming in the $80^{\text {th }}$ percentile of total consumption were significantly responsive to price, with a price elasticity of -0.74 that was much higher than that of moderate drinkers. Prior analyses that considered dichotomous indicators of heavy users found that binge drinkers and/or binge drinking days were more responsive to changes in price than light or infrequent drinkers. ${ }^{49,50}$

To what extent might the same logic apply to marijuana? The literature described here suggests that a non-linear relationship is certainly plausible. What little evidence we have on heavy users suggests price elasticities substantially larger than those estimated from past month users. But the literature is thin, due in part to relatively lousy data on potency-adjusted marijuana and due in part to lousy data on how much marijuana is consumed in a single use occasion across different types of users. We do know that regular users are sensitive to changes in the monetary price of marijuana. Prevalence estimates suggest that a ten percent decline in price could lead to a 2.4 to 2.5 percent increase in rates of use among regular users. Full consumption effects, which would also capture changes in the amount consumed among existing users (i.e., "conditional demand") may even be larger, as indicated by the full demand and conditional demand elasticities identified in the US literature. The sensitivity of the conditional demand for marijuana to changes in prices in the US is consistent with findings from the alcohol and tobacco literature, which have consistently shown that quantities consumed among users are also sensitive to changes in price..$^{51-55}$

However, the frailty of the literature understanding the behavior of regular and heavy marijuana users leaves us with little basis on which to answer the most pressing question of our time: how will marijuana consumption change with legalization? Nonetheless, it is important to keep in mind that even if the literature were more complete, it is not clear that one could infer anything about consumption in a legalization regime based on price elasticity estimates generated from a prohibition regime. Legalization would bring more than just a potential reduction in the price of the substance; it will also bring a reduction in the legal risks of using the drug and the perceived harm, which we have demonstrated here have their own independent effects on demand. Thus, the honest answer is that we simply do not know and will not know 
until evaluations of the current state experiments in Colorado and Washington, where recreational use of marijuana has recently been legalized, are carefully conducted.

\section{SUMMARY AND CONCLUSIONS}

The research reviewed here provides insights into discussions regarding legalization. In particular, it is clear from the literature that the demand for marijuana is responsive to changes in both its monetary price and the nonpecunary aspects of price, particularly those pertaining to legal risk. However, the responsiveness of demand varies depending on the type of policy change (price change versus criminal status change) and varies considerably across the type of user (light, casual, regular or heavy). This knowledge is useful for thinking about the effects of policy changes on consumption overall, as changes in the simple annual prevalence rate will not fully reflect changes in the distribution of users or the amount consumed in total. In particular prevalence rates over represent the behavior of light and casual users and discount the behavior of regular and heavy users, who generally represent a much smaller proportion of the total users even though they represent the majority of quantity consumed.

However, the findings cannot provide any sort of precise insight regarding how much consumption might change in response to a change in price or liberalization policy. A number of limitations remain in our current understanding of the impact of price on marijuana use. First and foremost, while a fairly robust literature has emerged analyzing the impact of price on the prevalence of marijuana use (in the past year or past month), very little work carefully considers the impact of price (and its full components) on the quantity consumed conditional upon using it. This is a major limitation in efforts to ascertain the impact of marijuana legalization on overall use and its effect on harms as those harms will most likely be associated with persistent regular or heavy use, not casual use. Similarly, tax revenue from sales will be more heavily influenced by the change in total amount consumed among existing users than the proportion of the population who decide to use any marijuana. Findings from the alcohol and tobacco literature suggest that quantities consumed among existing users are sensitive to changes in the monetary and non-pecuniary components of price ${ }^{49,56-57}$ and it is changes in these existing users that are likely to be the most relevant for understanding the impact on total consumption (and hence total revenue). But without an understanding of how much use would change in response to price changes, any estimate of the effect of consumption due to a change in legalization will grossly understate the effects on total consumption. 
Second, while changes in the monetary price of marijuana may be important for understanding how much consumption will change, other aspects of the change in policy, including the reduction in the legal risk and perceived harm of use, will also be important predictors of how much consumption actually changes. Thus, models attempting to project the impact of a change on consumption associated with legalization must make assumptions regarding not only the change in monetary price but also the anticipated change in perceived norms and legal risk. For example, the results of Pacula et al. suggest that a ten percent decrease in the perceived harm of marijuana would generate a 28.7 percent increase in annual prevalence of marijuana use among youth, a change substantially larger than the results of a small change in the monetary price, legal risks or law enforcement. ${ }^{11}$ Ignoring these factors would again lead to an understated estimate on consumption.

Third, evidence presented here suggests that all aspects of marijuana use could change in response to this policy change, with more new initiates, more regular users, and people using for longer periods of time. Summary measures from initiation suggest that for every ten percent decline in the monetary price of marijuana, there will be an increase of three to five percent in new marijuana users prior to the age of 18 , an increase of 2.5 percent in regular users, and an increase in the duration in which marijuana is used during adulthood. Absent more vigorous prevention efforts to counter these trends, the implication will be an expanding market, both in terms of the number of users and in the total quantity consumed by the market.

\section{Acronyms List:}

DSM-IV = Diagnostic and Statistical Manual of Mental Disorders, Fourth Edition NHSDA = National Household Survey on Drug Abuse NSDUH= National Survey on Drug Use and Health

Acknowledgements: Funding in support of this research was provided by a grant from the National Institute on Drug Abuse.

Conflicts of Interest: None declared.

\section{REFERENCES}

1. Caulkins JP, Pacula RL. Marijuana markets: inferences from reports by the household population. J Drug Issues. 2006;36:173-200.

2. Kilmer B, Pacula RL. Estimating the size of the global drug market: a demandside approach. RAND Technical Report TR-711. Santa Monica (CA): RAND Corporation; 2009. 
3. Kilmer B, Caulkins JP, Pacula RL, Reuter P. Bridging perspectives to illicit markets: estimating the size of the U.S. marijuana market. Drug Alcohol Depend. 2011;119:153-60.

4. Office of National Drug Control Policy. The economic costs of drug abuse in the United States, 1992-2002. Washington (DC): Executive Office of the President, ONDCP; 2004.

5. Kilmer B, Everingham S, Caulkins JP, Midgette G, Reuter P, et al. What America's users spend on illicit drugs: 2000-2010. Office of National Drug Control Policy; In press.

6. Kilmer B, Caulkins JP, Pacula RL, MacCoun RJ, Reuter PH. Altered state? Assessing how marijuana legalization in California could influence consumption and public budgets. RAND report OP-315. Santa Monica (CA): RAND Corporation; 2010.

7. Gieringer D. Practical experience with legalized cannabis. Addiction. 2012;107: 875-6.

8. Substance Abuse and Mental Health Services Administration. Results from the 2008 National Survey on Drug Use and Health: national findings. Office of Applied Studies, NSDUH Series H-36, HHS Publication No. SMA 09-4434. Rockville (MD): U.S. Department of Health and Human Services; 2009.

9. Bachman JG, Johnston LD, O’Malley PM. Explaining recent increases in students' marijuana use: impacts of perceived risks and disapproval, 1976 through 1996. Am J Public Health. 1998;88:887-92.

10. Bachman JG, Johnston LD, O’Malley PM. Smoking, drinking and drug use among American high school seniors: correlates and trends, 1975-1979. Am J Public Health. 1981;71:59-69.

11. Pacula RL, Grossman M, Chaloupka FJ, O’Malley P, Johnston LD, Farrelly MC. Marijuana and youth. In: Gruber J, (editor). Risky Behavior among Youths: An Economic Analysis. Chicago (IL): University of Chicago Press; 2001. p.271-326.

12. Pacula RL, Chriqui J, King J. Decriminalization in the United States: what does it mean? NBER Working Paper 9690. Cambridge (MA): National Bureau of Economic Research; 2003

13. Jacobson M. Baby booms and drug busts: trends in youth drug use in the United States 1975-2000. Q J Econ. 2005;119:1481-512.

14. van Ours JC, Williams J. Cannabis prices and dynamics of cannabis use. J Health Econ. 2007;26:578-96.

15. Bretteville-Jensen AL, Williams J. Decriminalization and initiation into cannabis. Presented at 4th annual meetings of the International Society for the Study of Drug Policy, Santa Monica, CA. 2010.

16. Johnston L, O’Malley P, Bachman J. Marijuana decriminalization: the impact on youth 1975-1980. Ann Arbor (MI): Institute for Social Research; 1981.

17. DiNardo J, Lemieux T. Alcohol, marijuana and American youth: the unintended consequences of government regulation. J Health Econ. 2001;20:991-1010. 
18. Markowitz S, Tauras J. Substance use among adolescent students with consideration of budget constraints. Rev Econ Household. 2009;7:423-46.

19. Pacula RL. Can increasing the beer tax reduce marijuana consumption? J Health Econ. 1998; 17:557-86.

20. Chaloupka FJ, Grossman M, Tauras JA. The demand for cocaine and marijuana by youth. In: Chaloupka FJ, Grossman M, Bickel W, Saffer H, (editors). The Economic Analysis of Substance Use and Abuse: An Integration of Econometric and Behavioral Economic Research. NBER Conference Report Series. Chicago (IL) and London: University of Chicago Press; 1999. p.133-55.

21. Chaloupka FJ, Pacula RL, Farrelly MC, Johnston LD, O’Malley PM. Do higher cigarette prices encourage youth to use marijuana? NBER Working Paper 6939. Cambridge (MA): National Bureau of Economic Research; 1999.

22. Farrelly M, Bray J, Zarkin G, Wendling B. The joint demand for cigarettes and marijuana. Evidence from the National Household Surveys on Drug Abuse. J Health Econ. 2001;20:51-68.

23. MacCoun, R, Pacula RL, Chriqui JF, Harris K, Reuter P. Do citizens know whether their state has decriminalized marijuana? Assessing the perceptual component of deterrence theory. Rev Law Econ. 2009;5:347-71.

24. Room R, Fischer B, Hall W, Lenton S, Reuter P. Cannabis policy: moving beyond the stalemate. The Global Cannabis Commission report. Oxford: The Beckley Foundation; 2008.

25. Nisbet CT, Vakil F. Some estimates of the price and expenditure elasticities of demand for marijuana among U.C.L.A. students. Rev Econ Statistics. 1972; 54:473-5.

26. Williams J, Pacula RL, Chaloupka FJ, Wechsler H. Alcohol and marijuana use among college students: economic complements or substitutes. Health Econ. 2004; 13:825-43.

27. Williams J, Pacula RL, Chaloupka FJ, Wechsler H. College students' use of cocaine. Subst Use Misuse. 2006;41:489-509.

28. Thies C, Register C. Decriminalization of marijuana and the demand for alcohol, marijuana and cocaine. Soc Sci J. 1993;30:385-99.

29. Saffer H, Chaloupka FJ. The demand for illicit drugs. Econ Inquiry. 1999;37: 401-11.

30. Saffer H, Chaloupka FJ. Demographic differentials in the demand for alcohol and drugs. In: Chaloupka FJ, Grossman M, Bickel W, Saffer H, (editors). The Economic Analysis of Substance Use and Abuse. Chicago (IL): University of Chicago Press; 1999.

31. Farrelly MC, Bray JW, Zarkin GA, Wendline BW, Pacula RL. The effects of prices and policies on the demand for marijuana: evidence from the National Household Surveys on Drug Abuse. NBER Working Paper 6940. Cambridge (MA): National Bureau of Economic Research; 1999.

32. DeSimone J, Farrelly MC. Price and enforcement effects on cocaine and marijuana demand. Econ Inquiry. 2003;41:98-115. 
33. Rhodes W, Johnson P, Han S, McMullen Q, Hozik L. Illicit drugs: price elasticity of demand and supply. Cambridge (MA): Abt Associates Inc.; 2001.

34. Clements K, Zhao X. Economics and marijuana. Cambridge: Cambridge University Press; 2009.

35. Ramful P, Zhao X. Participation in marijuana, cocaine and heroin consumption in Australia: a multivariate probit approach. Applied Econ. 2009;41:481-96.

36. Williams J, Mahmoudi P. Economic relationship between alcohol and cannabis revisited. Econ Record. 2004;80:36-48.

37. Clements K, Daryal M. The economics of marijuana consumption. In: Selvanathan E, Selvanathan S, (editors). The Demand for Alcohol, Tobacco, Marijuana and other Evils. London: Ashgate; 2003.

38. Cameron L, Williams J. Substitutes or complements? Alcohol, cannabis and tobacco. Econ Record. 2001;77:19-34.

39. Williams J. The effects of price and policies on cannabis consumption. Health Econ. 2004;13:123-37.

40. Zhao X, Harris M. Demand for marijuana, alcohol and tobacco: participation, levels of consumption and cross-equation correlations. Econ Record. 2004; 80:394-410.

41. Gallet CA. Can price get the monkey off our back? A meta-analysis of illicit drug demand. Health Econ. 2014;23:55-68.

42. Model K. The effect of marijuana decriminalization of hospital emergency room drug episodes: 1975-1978. J Am Statistical Assoc. 1993;88:737-47.

43. Makkai T, Fitzgerald J, Doak P. Drug use among police detainees. Contemporary Issues in Crime and Justice. Sydney: NSW Bureau of Crime Statistics and Research; 1996.

44. Pacula RL, Kilmer B. Marijuana and crime: is there a connection beyond prohibition? NBER Working Paper 10046. Cambridge (MA): National Bureau of Economic Research; 2003.

45. Grossman M. Individual behaviors and substance use: the role of price. In: Lindgren B, Grossman M, (editors). Substance Use: Individual Behaviour, Social Interactions, Markets and Politics. Amsterdam: Elsevier; 2005.

46. van Ours JC. Dynamics in the use of drugs. Health Econ. 2006;15:1283-94.

47. Pudney S. Keeping off the grass? An econometric model of cannabis consumption in Britain. J Applied Econometrics. 2004;19:435-53.

48. Manning WG, Blumberg L, Moulton L. The demand for alcohol: the differential response to price. J Health Econ. 1995;14:123-48.

49. Grossman M, Chaloupka FJ, Saffer H, Laixuthai A. Effects of alcohol price policy on youth: a summary of economic research. J Res Adolescence. 1994; 4:347-64.

50. Kenkel DS. Drinking, driving and deterrence: the effectiveness and social costs of alternative policies. J Law Econ. 1993;36:877-913.

51. Chaloupka FJ, Wechsler H. Price, tobacco control policies and smoking among young adults. J Health Econ. 1997;16:359-73. 
52. Chaloupka FJ, Grossman M. Price, tobacco control policies and youth smoking. NBER Working Paper 5740 Cambridge (MA): National Bureau of Economic Research; 1996.

53. Lewit E, Coate D. The potential for using excise taxes to reduce smoking. J Health Econ. 1982;1:121-45.

54. Harris JE, Chan SW. The continuum-of-addiction: cigarette smoking in relation to price among Americans aged 15-29. Health Econ. 1999;8:81-6.

55. Chaloupka FJ, Warner KE. The economics of smoking. In: Culyer AJ, Newhouse JP, (editors). Handbook of Health Economics. First Edition. Amsterdam: Elsevier; 2000. Vol.1, Ch.29, p.1539-627.

56. Hseih CR. Health risk and the decision to quit smoking. Applied Econ. 1998; 30:795-804.

57. Hu TW, Sung HY, Keeler TE. Reducing cigarette consumption in California: tobacco taxes vs an anti-smoking media campaign. Am J Public Health. 1995;85:1218-22.

58. Chaloupka FJ, Pacula RL. Economics and anti-health behavior: the economic analysis of substance use and abuse. In: Bickel W, Vuchinich R, (editors). Reframing Health Behavior Change with Behavioral Economics. Hillsdale (NJ): Lawrence Earlbaum Associates; 2000. p.89-111. 